Várhegyi et al., Effects of sample origin, extraction and hot water washing on devolatilization kinetics, Page 1 of 26

This manuscript was accepted and published by Industrial \& Engineering Chemistry Research, a journal of the American Chemical Society.

Publication data of the final, corrected work:

Várhegyi, G.; Grønli, M. G.; Di Blasi, C.: Effects of sample origin, extraction and hot water washing on the devolatilization kinetics of chestnut wood. Ind. Eng. Chem. Res. 2004, 43, 2356-2367. doi: $\underline{10.1021 / \mathrm{ie} 034168 \mathrm{f}}$

\title{
EFFECTS OF SAMPLE ORIGIN, EXTRACTION AND HOT WATER WASHING ON THE DEVOLATILIZATION KINETICS OF CHESTNUT WOOD
}

\author{
Gábor Várhegyi ${ }^{\dagger}$, Morten Gunnar Grønli, Colomba Di Blasi ${ }^{*} \S$
}

†Institute of Materials and Environmental Chemistry, Chemical Research Center, Hungarian Academy of Sciences, P.O. Box 17, Budapest 1525, Hungary. Email: varhegyi.gabor@ttk.mta.hu

\author{
‡SINTEF Energy Research, Department of Energy Processes, N-7034 Trondheim, Norway \\ ${ }^{\S}$ Dipartimento di Ingegneria Chimica, \\ Università degli Studi di Napoli "Federico II", P.le V. Tecchio, 80125 Napoli - Italy
}

*Corresponding author, email: diblasi@unina.it

\begin{abstract}
The variations in chemical composition and the effects of sample origin and pre-treatments represent a major problem in the kinetic modeling of wood pyrolysis. This study aims to a deeper understanding of these issues by examining a species, chestnut (Castanea sativa), that contains a higher amount of extractives than the common forest hardwoods of the temperate zone. Thermogravimetric and kinetic analysis were carried out on five chestnut samples obtained from plants grown in France, Italy and Russia. The results were compared to that of a widely used and investigated species (beech) belonging to the same plant family. Degradation takes place over a narrower range and at lower temperatures, giving higher yields of char. In all cases, hot water washing causes a decrease in the fixed carbon content and char yield, an increase in the peak rate, a better separation between pseudo-component dynamics and a displacement of the reaction zones toward higher temperatures. Though with some scatter and quantitatively lower, the same effects are also observed as a consequence of acetone extraction. Both pre-treatments act to reduce the differences between chestnut samples and with beech, but peculiarities due to origin and species are preserved. The three parallel reaction mechanism for the hemicellulose, cellulose and lignin, with the same activation energies previously determined for other hardwood species by Grønli et al. (Ind. Eng. Chem. Res. 2002, 41, 4201) is still acceptable for engineering applications. On the contrary, predictions of the process details require single
\end{abstract}


curves evaluations, resulting in kinetic data specific to sample origin, except for the activation energy of the lignin devolatilization step. Kinetic parameters also indicate that the lower char yields, associated with pretreatments, are chiefly due to alterations in the cellulose decomposition kinetics, whereas the effects on the other two components nearly compensate each other. Finally, reliable evaluations are provided of experimental uncertainties associated with repeatability of experiments and reproducibility of sample properties.

\section{INTRODUCTION}

Computer codes of detailed mathematical models, coupling the chemical kinetics of wood pyrolysis, gasification and combustion with the conservation equations for heat, mass and momentum transfer, are advanced tools for the design and optimization of chemical reactors for thermochemical conversion processes. Also, the knowledge of fuel reactivity is needed to formulate simple rules for empirical design and scale-up. A recent study carried out by Grønli et al. ${ }^{1}$ examines the thermogravimetric curves of nine wood species with chemical composition lying within the standard range for hardwoods and softwoods. It shows that a unified devolatilization mechanism, consisting of three parallel reactions and the same set of activation energies for the pseudo-components hemicellulose, cellulose and lignin (100, 236 and $46 \mathrm{~kJ} / \mathrm{mol})$, can describe well the high-temperature (> 553K) degradation. The extension of the mechanism at lower temperatures requires, in a few cases, two further reactions with activation energies equal to 105 and $127 \mathrm{~kJ} / \mathrm{mol}$.

Previous experimental analyses ${ }^{2,3}$ on the pyrolysis of thick cylinders and packed beds of particles report significant differences between chestnut (a hardwood) and other (standard) hardwoods and softwoods. Chestnut produces char in a very high yield and undergoes significant degradation already at relatively low temperatures. The sample, derived from a species grown in Italy, is characterized by a high content of extractives, which results in a diminished holocellulose contribution, compared with other hardwoods. Acetone extraction is observed ${ }^{3}$ to reduce the differences between chestnut and the other wood species. However, no quantitative information can be obtained on the reaction kinetics, due to the dominant role played by transport phenomena in the experiments carried out. On the other hand, it cannot be excluded that the peculiarity of the chestnut sample examined is due only to the origin of the plant and/or that other sample pre-treatments can be more effective in eliminating the compounds responsible for the differences in the pyrolysis rate and products.

Following the peculiar behavior previously observed, ${ }^{2,3}$ the global devolatilization kinetics of chestnut is examined in this study by means of thermogravimetry. More precisely, the investigation is carried out for five samples, of different origin, and their counterparts submitted to acetone extraction or hot water washing. 
Such aspects have not been systematically investigated for any wood species in previous literature (especially no study is currently available on the effects of sample origin). The aim of the paper is twofold: 1) to quantify the influences of sample origin and pre-treatments on the degradation characteristics of chestnut wood when the process is controlled by chemical kinetics, and 2) to understand whether the unified mechanism proposed by Grønli et al. ${ }^{1}$ is also valid for wood species with a non-standard chemical composition/behavior.

\section{EXPERIMENTAL ANALYSIS AND KINETIC MODELING Material and Experimental Procedure}

The experiments have been carried out on five chestnut samples (Castanea sativa), derived from knot- and bark-free logs. The influences of the different parts of the plant on the decomposition process are outside the scope of this work, but it is acknowledged that this subject, not systematically examined in the literature, is worth future investigation. The plants were grown in different geographical areas: one in France (indicated in the following as F), two in Italy (I1 and I2), and two in Russia (R1 and R2). The sample I1 is the same used in the experiments reported by Di Blasi and coworkers. ${ }^{2,3}$ Its chemical composition consists of: $16 \%$ extractives, $18 \%$ lignin and $66 \%$ holocellulose (by difference). The extractive content (1g of biomass extracted with $60 \mathrm{ml}$ of acetone in a Soxhtec HT2, using residence times for the boiling and rising stages of 90 and 20min, respectively, and a plate temperature of $363 \mathrm{~K}$ ) has also been determined in the other cases and reported in Table 1A. (The tables are collected at the end of this document.) It varies with the origin of the sample, resulting in quite high values for the samples I2, R2 and R1 (8.5-5.8\%) and barely higher than the usual standards for the sample F. Beech wood is used all through the paper for comparison (the extractive content is listed in Table 1A). Indeed, both chemical composition and devolatilization characteristics of this species are roughly coincident with the average values reported for standard hardwoods. ${ }^{1}$

Extractives which, for a given species, may vary owing to the site where plants are grown and the amount of heartwood, are a complex mixture ${ }^{4}$ of low molecular weight sugars, inositols, amino acids, simple fats, carboxylic acids, terpenes and phenolic compounds. Specific to chestnut extractives is the presence of tannins. $^{3}$ In addition to the extracted chestnut samples indicated in the following with the abbreviation E (FE, I1E, I2E, R1E and R2E, respectively) and beech, extractives from samples I1, I2, R1 and R2 have been collected and investigated.

Water washing has received a great deal of attention as a mean to eliminate alkali metals from herbaceous biomass, thus mitigating their noxious effects in relation to fouling and slagging during combustion. ${ }^{5-8}$ Moreover, this pre-treatment has been used to improve peak resolution in thermogravimetric curves and to simplify in-situ investigation of cellulose decomposition kinetics. ${ }^{9-10}$ Hot-water washing (1g of wood and $100 \mathrm{ml}$ of distilled water for two hours at $333 \mathrm{~K}$ in a stirred vessel) has also been applied to chestnut samples, 
which in the following analysis are indicated with the abbreviation $\mathrm{W}$ (FW, I1W, I2W, R1W and R2W, respectively), and beech.

In order to clarify the possible role played by the chemistry of wood components on the deviations of chestnut wood with respect to standard hardwood species during thermal decomposition, thermogravimetric curves have also been measured for three lignin samples. They were obtained, following the Klason method, from untreated samples of beech and chestnut I1 and from an extracted sample of chestnut I1.

The proximate analyses of chestnut samples are also listed in Table 1A. Data on beech wood are included for comparison. Compared with beech, the fixed carbon content is higher for the chestnut samples (15-22\% versus 13\%). Variations in the proximate analyses of wood samples due to pre-treatments can also be seen. Hot water washing always causes a significant decrease in the fixed carbon content (factors of $18-46 \%$ for chestnut samples and 30\% for beech). Apart from beech and the sample F, which show a small increase, the effects of extraction are qualitatively similar but quantitatively lower (reduction in the fixed carbon content between $7-32 \%)$.

As shown by means and standard deviations (Table 1A), both hot water washing and acetone extraction act to reduce the differences between chestnut samples due to origin. Using the means as representative of chestnut properties, it can be observed that differences are also reduced with respect to beech for the samples subjected to a hot water treatment. They are also higher than those due to origin. In conclusion, both pre-treatments are not capable of making coincident the proximate analyses of the different chestnut samples and beech.

Table 1B reports the proximate analyses of the four extractives and the three lignin samples. For both cases, quite high values of the fixed carbon content are found. For extractives, values are between $30-32 \%$. As for lignin, the wood species does not appear to play any role (about $47 \%$ for untreated beech and chestnut) but extraction does (43\% for extracted chestnut).

A TA Instruments SDT 2960 simultaneous TG-DTA apparatus has been employed for the thermogravimetric tests. ${ }^{1}$ This apparatus detects the mass loss with a resolution of $0.1 \mu \mathrm{g}$ and the temperature is measured in the sample holder. High purity nitrogen has been used for the tests at a flow rate of $150 \mathrm{ml} / \mathrm{min}$. It has been purged for $20 \mathrm{~min}$, before starting the heating program, in order to established an inert environment. The experiments have been started with a drying session (a heating rate of $30 \mathrm{~K} / \mathrm{min}$ up to $383 \mathrm{~K}$ with a holding time of 30min). The subsequent thermal decomposition has been carried out at a slow heating rate $(5 \mathrm{~K} / \mathrm{min}$ to a final temperature of $773 \mathrm{~K}$ ), to keep possible heat/mass transfer intrusions at minimum, with a sample mass of 5mg and particle sizes below $0.25 \mathrm{~mm}$. These are sufficiently small to avoid intra-particle gradients given 
that an eightfold difference in the level of grinding $(1-0.12 \mathrm{~mm})$ has been recently found ${ }^{11}$ to have only minor effects on the thermal decomposition of biomass.

The repeatability of pretreatments and the reproducibility of the sampling strategy (possible variations in the properties for samples obtained from the same tree or trees grown in the same geographical area) have also been investigated. As for the first point, thermogravimetric measurements have been carried out on beech samples previously subjected to three separate tests for acetone extraction and hot water washing, respectively. The tree-to tree variation of the characteristics within a forest was determined in an earlier project by M. G. Grønli. Birch samples from three trees growing on different types of soil were investigated and have been re-examined in this study. The repeatability of thermogravimetric experiments has also been assessed by using measurements carried out on untreated (6), extracted (5) and water washed (4) beech samples over a period of about two years.

\section{Kinetic modeling}

The three-step model with linear or non-linear dependence on species concentrations, for the volatile fractions of hemicellulose, cellulose and lignin, has been widely applied 9,10,12-19 to describe thermogravimetric curves of wood/biomass devolatilization obtained under dynamic conditions. Sometimes it has been modified to include additional steps for improving the accuracy of the predictions ${ }^{1,11,20}$. Isothermal measurements have been modeled either with one-step or multi-step mechanisms as shown in the literature reviews of two recent papers ${ }^{21,22}$. In a few cases nucleation models and discrete activation energy models have also been proposed. ${ }^{23}$

The three-step linear model is chosen in this study as it requires a relatively low number of parameters and can be easily coupled with transport equations for modeling practical systems. The amount of volatiles produced by the $j$ th component of a unit mass of sample between $t=0$ and $t=\infty$ is indicated by the parameters $c_{j}\left(\mathrm{j}=\mathrm{hc}\right.$ (hemicellulose), c (cellulose), 1 (lignin)). These, and the corresponding kinetic constants $\left(A_{j}\right.$ and $E_{j}$, pre-exponential factor and activation energy, respectively), are estimated by means of a least squares evaluation of the differential curves (the final char yield can be calculated from the $c_{j}$ values, given that the summation of volatile and solid products is equal to 1). The fit between calculated (calc) and observed (obs) $\mathrm{dY} / \mathrm{dt}$, for each time, $\mathrm{t}_{\mathrm{i}}$, is characterized by the following variable:

$$
f i t(\%)=100\left(\sum_{i=1}^{N_{k}}\left\{[\mathrm{dY} / \mathrm{dt}]_{i k}{ }^{o b s}\left(\mathrm{t}_{\mathrm{i}}\right)-[\mathrm{dY} / \mathrm{dt}]_{i k}{ }^{\text {calc }}\left(\mathrm{t}_{\mathrm{i}}\right)\right\}^{2} / N_{k}\right)^{1 / 2} / \mathrm{h}_{\mathrm{k}}
$$

where $N_{k}$ is the number of points on the $k$ th evaluated curve $\left(N_{k}\right.$ varied between 500 and 1000 in the calculations) and $h_{k}$ denotes the height of $k$ th evaluated curve. 
It has been suggested ${ }^{11,19}$ that, to avoid compensation effects in the estimation of the kinetic constants, different heating rates should be considered. In the present paper only one heating rate $(5 \mathrm{~K} / \mathrm{min})$ is examined because of the high number of experiments carried out to investigate the effects of sample origin and pretreatments (25), to evaluate the repeatability of thermogravimetric measurements (15) and pretreatments (6) and to assess the role of sampling strategy (3). Then, the kinetic evaluation is made only for measurements carried out at $5 \mathrm{~K} / \mathrm{min}$. This, however, does not impugn the validity of the present results. Indeed, the threestep linear model has already been shown to predict well thermogravimetric curves of rice hulls obtained for a wide range $(3-100 \mathrm{~K} / \mathrm{min})$ of heating rates, ${ }^{13}$ providing variations on the pre-exponential factors (the activation energies are barely different from those of the present study). It should also be mentioned that norder reaction rates for the three-step model have resulted in activation energies for the decomposition of the hemicellulose and lignin components ${ }^{16-18}$ significantly different from those used here. It can be understood that, in general, by increasing the number of parameters, the accuracy of the predictions is increased, but this appears to be a formal consequence of the increased number of freedom in the models. Given the global nature of the reaction kinetics and the composite nature of wood, it is possible that changes in the definitions of the pseudo-components give rise to different kinetic models and constants. These aspects should be investigated in future systematic studies.

\section{RESULTS AND DISCUSSION}

Results are presented and discussed into two parts, the first dealing with the devolatilization characteristics evaluated by means of the measured thermogravimetric curves and the second with the kinetic constants estimated for the three-parallel reaction mechanism.

\section{Devolatilization Characteristics of Wood}

The mass fraction, $\mathrm{Y}$, and the time derivative of the mass fraction, - $\mathrm{dY} / \mathrm{dt}$, (indicated as TG and DTG curves in the following) are reported as functions of temperature in Figs.1A-1B for the untreated chestnut and beech samples. The shape of the rate curves is qualitatively similar in all cases and allows the usual reaction zones, extensively discussed in the literature, to be seen. The quantitative characteristics of the thermogravimetric curves are summarized in Table $2 \mathrm{~A}$ in terms of several temperatures, introduced by Grønli et al., ${ }^{1}$ that is, $\mathrm{T}_{\text {initial }}$ (the beginning of the decomposition process, corresponding to $\mathrm{Y}=0.975$ ), $\mathrm{T}_{\text {onset }}$ (the beginning of

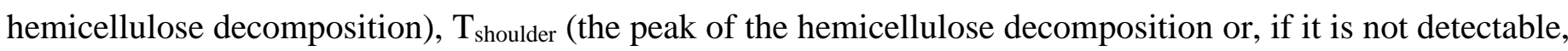
the point of the lowest slope of the DTG curve in this region), $\mathrm{T}_{\text {peak }}$ (the maximum devolatilization rate), and $\mathrm{T}_{\text {offset }}$ (the beginning of the final, tailing region dominated by lignin decomposition). Table $2 \mathrm{~B}$ reports the solid mass fractions and the devolatilization rates, corresponding to the characteristic temperatures, together with the yield of char, $\mathrm{Y}_{773}$ ( the solid mass fraction detected for $\mathrm{T}=773 \mathrm{~K}$ ). 

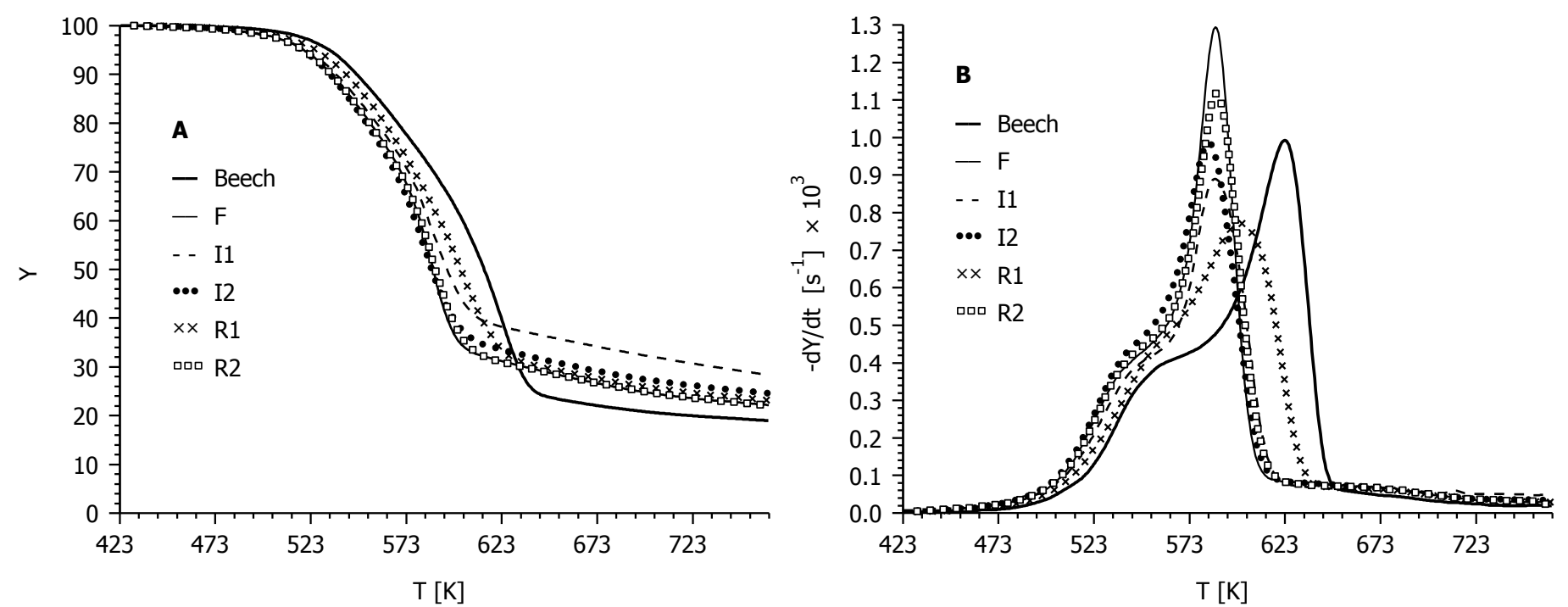

Figure 1. TG (A) and DTG (B) curves of untreated beach and chestnut (F, I1, I2, R1, R2) samples.

The origin of the sample influences quantitatively the devolatilization characteristics. The DTG curves for samples F, I1, I2 and R2 are similar, whereas sample R1 shows significant deviations. Indeed, degradation, on the average, occurs at higher temperatures and over a wider zone (Table 2A). Samples R1 and R2 exhibit lower peak rates than the other samples, leading to high ratios $(\mathrm{dY} / \mathrm{dt})_{\text {shoulder }} /(\mathrm{dY} / \mathrm{dt})_{\text {peak }}$ (values of 0.47 and 0.62 , respectively). The weight loss curves of the two samples grown in Italy coincide for temperatures below $478 \mathrm{~K}$ and above $603 \mathrm{~K}$, whereas for the two Russian samples the accordance is limited to very low $(<473 \mathrm{~K})$ or very high $(>643 \mathrm{~K})$ temperatures. On the whole, differences between chestnut samples are small for the initial part of the degradation curve (maximum differences of $6-7 \mathrm{~K}$ for $\mathrm{T}_{\text {initial }}$ and $\mathrm{T}_{\text {onset(hc), }}$, respectively), increase in the central zone (maximum differences of $17 \mathrm{~K}$ for $\mathrm{T}_{\text {shoulder }}$ and $\mathrm{T}_{\text {peak }}$ ) and attain their maximum along the tail (maximum differences of $28 \mathrm{~K}$ for $\mathrm{T}_{\text {offset }(\mathrm{c})}$ ) (see also the standard deviations with respect to means, Tables 2A-2B). The char mass fractions are comprised between 0.28-0.22.

Figures 1A-1B and Tables 2A-2B also permit a comparison between beech and chestnut. The very peculiar behavior of chestnut woods, already observed for thick samples, ${ }^{2,3}$ is confirmed. The differences are large for all the variables, in particular the position of the peak rate ( $\mathrm{T}_{\text {peak }}$ values anticipated of 22-39K) and the yields of char (positive deviations up to $46 \%$ ).

From the quantitative point of view, the differences in the characteristic devolatilization temperatures due to sample origin are lower than those between chestnut and beech. Indeed, standard deviations with respect to means for the chestnut temperatures (Table $2 \mathrm{~A}$ ) are comprised between $3-11 \mathrm{~K}$. On the contrary, using the means as representative of chestnut values, a comparison with beech leads to values between $6-23 \mathrm{~K}$. The same trend is also shown by the characteristic mass fractions with standard deviations varying between 0.020.03 (chestnut samples) and 0.02-0.1 (chestnut and beech). 
An example of the effects caused by the pre-treatments is shown in Figs. 2A-2B by means of the TG and DTG curves measured for the sample R1 and beech, respectively. Tables 2A-2B summarize the results in terms of the devolatilization parameters previously introduced. Independently of the methodology applied, trends are similar for both chestnut and beech with stronger effects associated with hot water washing. Previous findings $\mathrm{s}^{9,10,24,31}$ are confirmed, that is, sample pre-treatments offer a procedure for separating and sharpening the peaks, with also an increase in the reaction temperature (in particular, $\mathrm{T}_{\text {peak}}$ ) and a reduction in the yields of char. As clearly shown by Figs. 2A-2B, hot water washing causes a displacement of the entire thermogravimetric curves towards higher temperatures, though the effects are less pronounced for the hemicellulose zone (left side of the curves). The displacement is essentially limited to the cellulose and tail regions (right side of the curves) in the case of extraction.
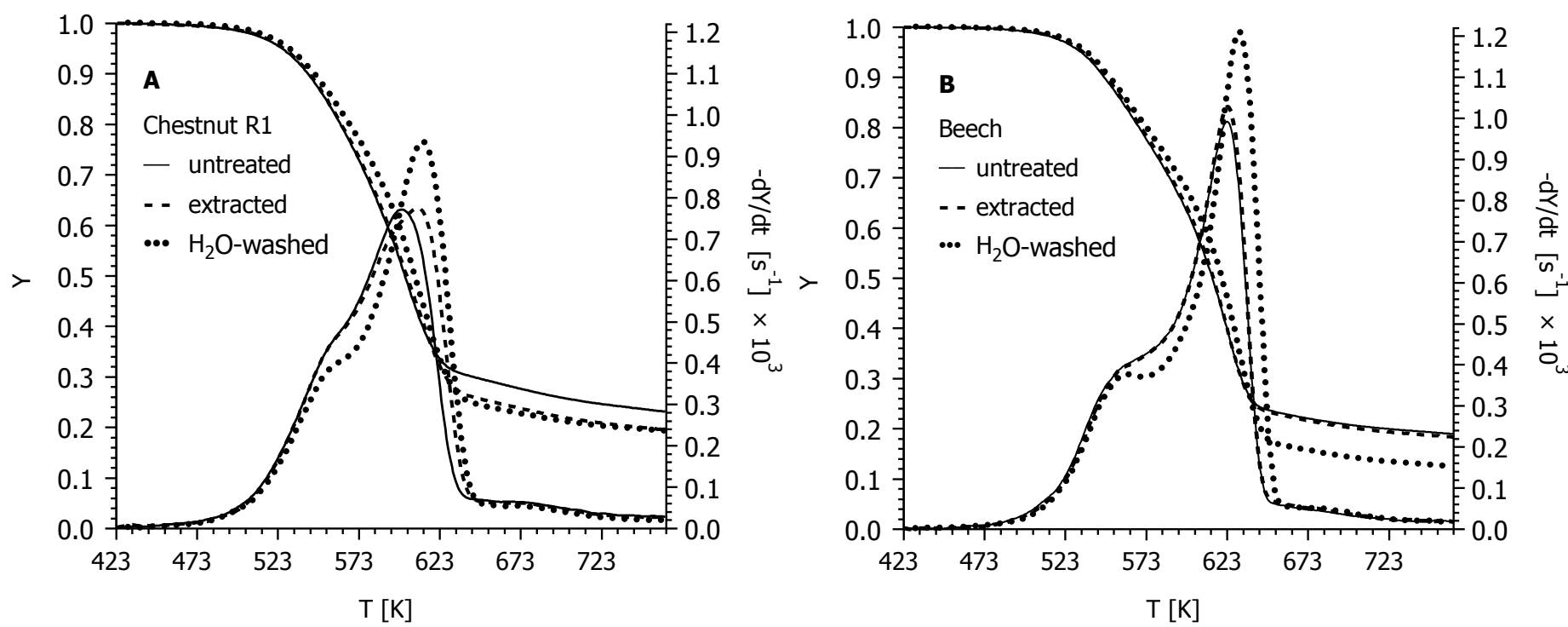

Figure 2. Effect of extraction and hot water washing on the thermal behavior of a chestnut (A) and the beech (B) sample.

In quantitative terms, for the hemicellulose region of the chestnut samples, variations on $\mathrm{T}_{\text {initial }}$, $\mathrm{T}_{\text {onset(hc), }}$, and $\mathrm{T}_{\text {shoulder }}$ are always below $10 \mathrm{~K}$ for water washing and $4 \mathrm{~K}$ for extraction. The width of the hemicellulose zone, $\mathrm{T}_{\text {shoulder }}-\mathrm{T}_{\text {onset(hc), }}$, remains roughly unchanged or is barely enlarged. As a consequence of the weak effects on the characteristic temperatures, $Y_{\text {shoulder }}$ values are practically independent of sample pre-treatment. The peak rate in this region, $(\mathrm{dY} / \mathrm{dt})_{\text {shoulder }}$, is also weakly affected by pre-treatments, except for the Russian samples.

As anticipated, the strongest effects caused by pre-treatments are the higher peak rates (Table 2B) and the improved separation (Table 2A) between the shoulder and the peak regions of the DTG curves. The displacement towards higher temperatures of the cellulose peak for the chestnut samples is especially high for hot water washing giving $\Delta \mathrm{T}_{\text {peak }}=13-20 \mathrm{~K}$ and $\Delta \mathrm{T}_{\text {offset(c) }}=8-17 \mathrm{~K}$ (against $1-10 \mathrm{~K}$ and $2-14 \mathrm{~K}$, respectively, for extraction). Similar to the hemicellulose zone, the width of the cellulose zone, $\mathrm{T}_{\text {offset(c) }}-\mathrm{T}_{\text {peak }}$, is only weakly affected though there is some scatter on the data. On the other hand, the entire reaction zone, $\mathrm{T}_{\text {offset(c) }}-\mathrm{T}_{\text {onset(hc), }}$ 
and that of the high rates, $\mathrm{T}_{\text {peak }}-\mathrm{T}_{\text {shoulder, }}$, are enlarged. For instance, for hot water washing, such enlargement corresponds to 7-12K and 9-12K, respectively. In other words, the extension of region where hemicellulose or cellulose degrade appears to be almost independent of the pre-treatments, which only affect the relative position and overlap between the two zones. Finally, the effects of pre-treatments are dependent on the sample origin. For instance, with reference to $\mathrm{T}_{\text {peak }}$ and hot water washing, the lowest sensitivity is shown by the sample R1 and the highest by the sample I1, indicating that the nature of the eliminated compounds is affected by the geographical area where the plants are grown.

In agreement with the results previously reported, ${ }^{3}$ extraction and mainly hot water washing cause a significant decrease in the yield of char from chestnut decomposition. Measurements show reductions in the range $14-28 \%$ (extraction) or 18-39\% (hot water washing), with an increase in the peak rates. The exception is represented by the extracted sample F, when a very small increase is observed (4.\%). It is worth observing that the dependence of the char yield on the sample origin or pre-treatment is the same as that of the fixed carbon content of the wood samples. This finding is a further confirmation of the direct correlation proposed by Antal et al. ${ }^{25}$ between these two parameters.

The differences in the hemicellulose zone of the DTG curves, already small for the untreated chestnut samples, are further reduced as a consequence of the pre-treatments (standard deviations for $\mathrm{T}_{\text {initial }}, \mathrm{T}_{\text {onset(hc) }}$ and $\mathrm{T}_{\text {shoulder }}$ become smaller (Table 2A), except for $\mathrm{Y}_{\text {peak }}$ ). Hot water washing also reduces the differences for

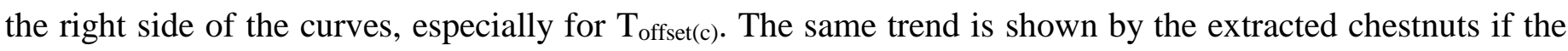
sample R1 is disregarded. However, it is worth observing that none of the two pre-treatments is capable of eliminating the effects due to sample origin.

Compared with chestnut, the effects of pre-treatments are smaller for beech wood. Indeed, $\mathrm{T}_{\text {initial, }}$, and $\mathrm{T}_{\text {onset(hc) }}$ show a small increase ( 2 and $4 \mathrm{~K}$ ), $\mathrm{T}_{\text {shoulder (as well as the width of the holocellulose degradation zone) }}$ remains unchanged, $\mathrm{T}_{\text {peak }}$ is constant (extraction) or slightly increases (by $9 \mathrm{~K}$, hot water washing) and the enlargement of the entire reaction zone is quite narrow $(7 \mathrm{~K})$. In the case of hot water washing, a decrease in the char yield (by a factor of $35 \%$ ) is also observed.

The properties of extracted and washed beech (Tables 2A-2B) can be compared with the means reported for the chestnut samples. Both pretreatment reduced the difference between the two species. Nevertheless, the difference between the means of the chestnut properties and beech is still higher than the variation within the chestnut samples.

Tables 2A-2B also report the experimental uncertainties of the devolatilization characteristics. These values 
are the root mean squares of the corresponding standard deviations calculated for 9 tests concerning the repeatability of pretreatments and reproducibility of sampling strategy (Estimation 1 of the experimental uncertainty) and 15 thermogravimetric tests on beech wood (Estimation 2 of the experimental uncertainty). In all cases they are much lower than the standard deviations of the chestnut devolatilization characteristics, that is, the differences caused by sample origin are much higher than those associated with the repeatability/reproducibility of the experimental data. Comparable values of the experimental uncertainties of the thermogravimetric measurements (Estimation 2) and the standard deviations for the water washed chestnut samples are observed only for the characteristic mass fractions (Table 2B).

Very scarce information is available on the thermal response of extractives and specifically on their intrinsic degradation characteristics. The measured TG and DTG curves of extractives from samples I1, I2, R1 and R2 are reported in Fig. 3. Degradation takes place with very slow (about one order of magnitude below those of the wood samples) and flat (three barely visible peaks at about 470-490K, 560-570K and 660-680K) rates over a very broad temperature range. These features, that is, a pyrolytic behavior comparable to a baseline, can be partially responsible for the limited effects caused by extraction on the weight loss characteristics of chestnut samples originated from different geographical areas. The yields of char from extractives are high, a finding which again correlates well with the fixed carbon content. It also supports the speculation ${ }^{2,3}$ that extractives intrinsically contribute in product distribution from the wood degradation. They have also been reported $^{26,27}$ to favor the formation of gaseous and solid (char) products (at the expense of liquids), owing to physical effects, that is, the prolonged residence times of vapors within the reacting sample.

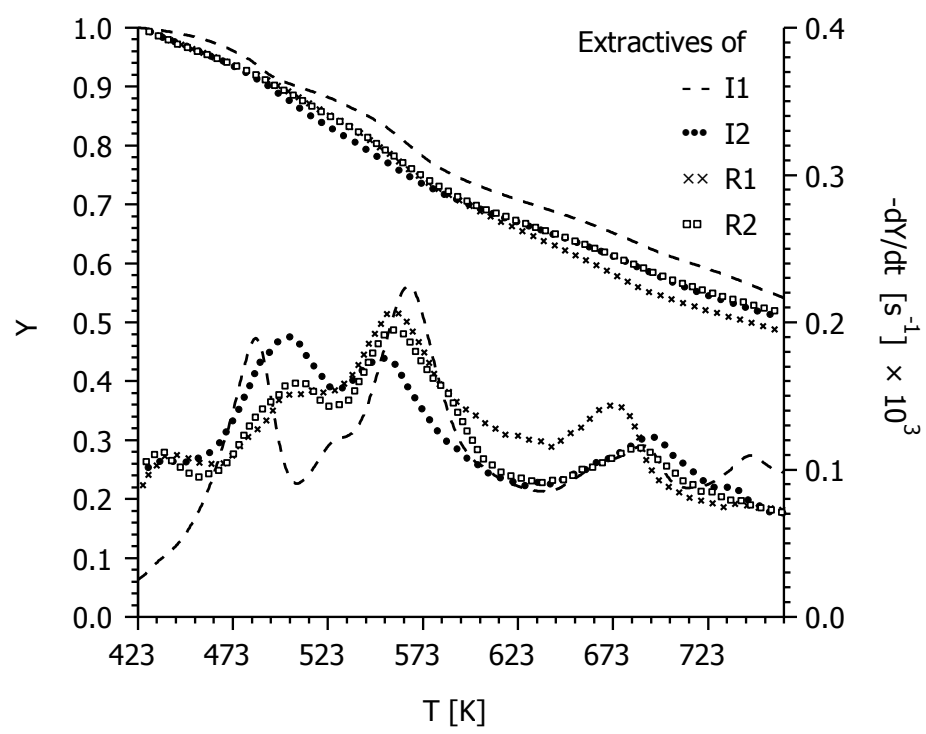

Figure 3. Thermal decomposition of the extractives prepared from various chestnut samples.

Some information on the weight loss characteristics of chestnut lignin (from untreated and extracted sample I1) can be obtained from Fig.4 (beech wood lignin is included for comparison). Extraction gives rise to slightly higher rates and lower yields of char, in accordance with the findings reported above for wood and 
the proximate analyses of the two samples. Common to both chestnut and beech lignin are the slow devolatilization rates over a very wide range of temperatures and the very high char yields. These results could suggest that the chemico-physical properties of the holocellulose fractions may be among the factors responsible for the significant differences still observed between the pre-treated chestnut and beech samples.

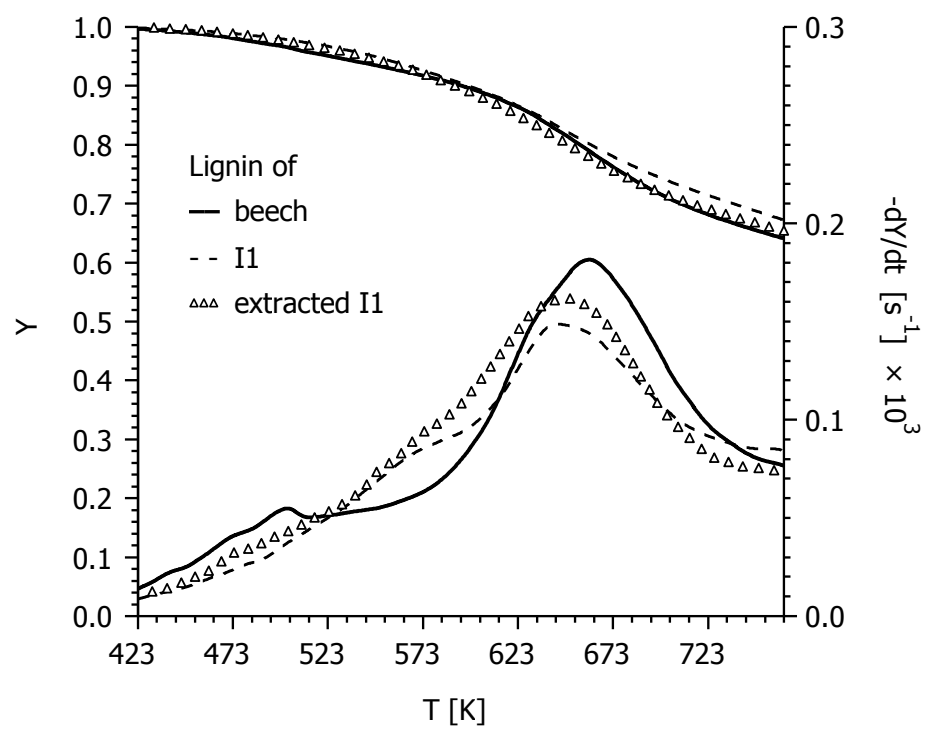

Figure 4. Thermal decomposition of lignins prepared from beech and chestnut.

The variations in the devolatilization characteristics, following pre-treatments, are a consequence of alterations in the chemical composition and probably the molecular structure of the woods. Hot water washing and acetone extraction mainly remove inorganics and extractives, respectively. In the former case, some sugars and phenolic compounds are also eliminated ${ }^{28}$ whereas, in the latter case, the loss of some inorganic matter has to be considered..$^{29}$ Moreover, it can be expected that, in the case of hot water treatment, hydrolysis of some organic compounds takes place at a certain extent. All these factors highly affect the products and degradation rate of the lignocellulosic fuels. It is reported ${ }^{30-32}$ that the metallic ions of the biomass exert a catalytic action which makes the degradation to occur at lower temperature and favors char formation. The important role played by the physico-chemical properties of cellulose on the decomposition kinetics is also well known. ${ }^{33}$ Actually, for the wood samples examined here, the partial removal of inorganics eliminates the associated catalytic action, the extraction of organic compounds eliminate the related intrinsic behavior/products and the possible cleavage of chemical bounds may influence reaction selectivity and rate. All these effects occur simultaneously though at a different extent depending on the specific treatment applied.

\section{Kinetic Evaluation}

The three parallel reaction model for the pseudo-components hemicellulose, cellulose and lignin is used to describe the degradation behavior of all the chestnut samples. The evaluation has been carried out over the temperature range $423-763 \mathrm{~K}$, by means of the DTG curves. On the basis of the similarity in the degradation 
behavior of lignins obtained from chestnut and beech woods, and in accordance with the kinetic analysis reported by Grønli et al., ${ }^{1}$ the activation energy for the volatile fraction of this component in wood has been taken constant and equal to $46 \mathrm{~kJ} / \mathrm{mol}$. A first evaluation has been carried out to assess the validity of the unified devolatilization mechanism previously proposed by Grønli et al. ${ }^{1}$ for standard hardwoods and softwoods. Hence, all the fifteen curves (untreated and pre-treated chestnut samples) have been evaluated with constraints on the activation energies for the hemicellulose and cellulose fractions. These have been taken constant and equal to 100 and $236 \mathrm{~kJ} / \mathrm{mol}$, respectively. The variation on the remaining parameters takes into account the sample differences illustrated above. Successively, in a more accurate analysis, the differential curves have been evaluated one by one, with no constraint apart from $\mathrm{E}_{\mathrm{l}}$, in order to quantify the influences of sample origin and pre-treatments in terms of kinetic parameters.

The result of the simultaneous evaluation of the chestnut curves with assigned activation energies are listed in Table 3 (three-step unified model) and examples of the best (fit=1.2\%, FW), typical (fit=2.2\%, I2) and worse (fit=3.3\%, I1E) agreement between model predictions and measurements are shown in Figs. 5A-5C. Table 4 reports the model predictions of the devolatilization parameters in terms of means and standard deviations. This description appears to be sufficient for the engineering practice but fails to predicts the details of the curves. The component dynamics reproduce trends in agreement with previous literature (for instance, see Grønli et al. ${ }^{1}$ ). The pre-exponential factors are less affected than the parameters $c_{j}$ by the origin and pretreatments of the samples. Compared with the results previously obtained for other woods, ${ }^{1}$ the unified model provides a less accurate fit (the mean of the fit is $2 \%$ with $\sigma=0.5$ against $1.25 \%$ with $\sigma=0.7$ ). 

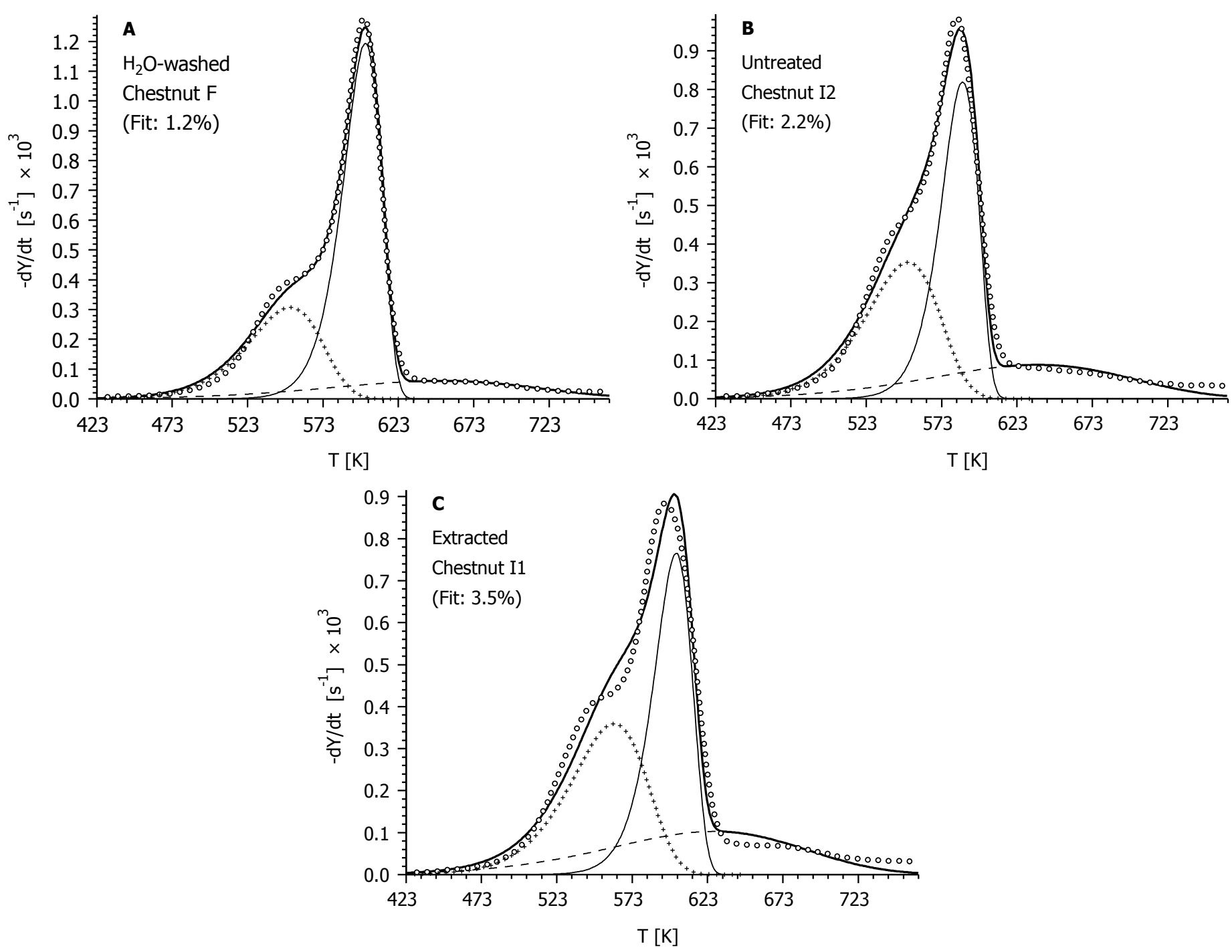

Figure 5. Comparison between the observed ( 0 o o ) and simulated (-) DTG curves employing the three-step unified model. The best fit (A), a typical fit (B) and the worse fit (C) are shown. Thin lines of different styles denote the simulated curves of the partial reactions. (See Table 3 for the corresponding parameters.)

The results of the evaluations carried out with no constraint on the activation energies of the hemicellulose and cellulose fractions are listed in Table 4 (three-step model) and examples of the best (fit $=0.6 \%, \mathrm{I} 2 \mathrm{~W}$ ), typical (fit=1.0\%, I2) and worse (fit=1.4\%, R1E) agreement between model predictions and measurements are shown in Figs. 6A-6C. Other information, obtained from the simulation of component dynamics, is summarized in Table 6 in terms means and standard deviations of peak height, width and temperature. As expected, the agreement between predictions and measurements improves significantly and is better than that of the unified model applied for standard woods $^{1}$ (the mean of the fit is $0.98 \%$ with $\sigma=0.21$ against $1.25 \%$ with $\sigma=0.7)$. 

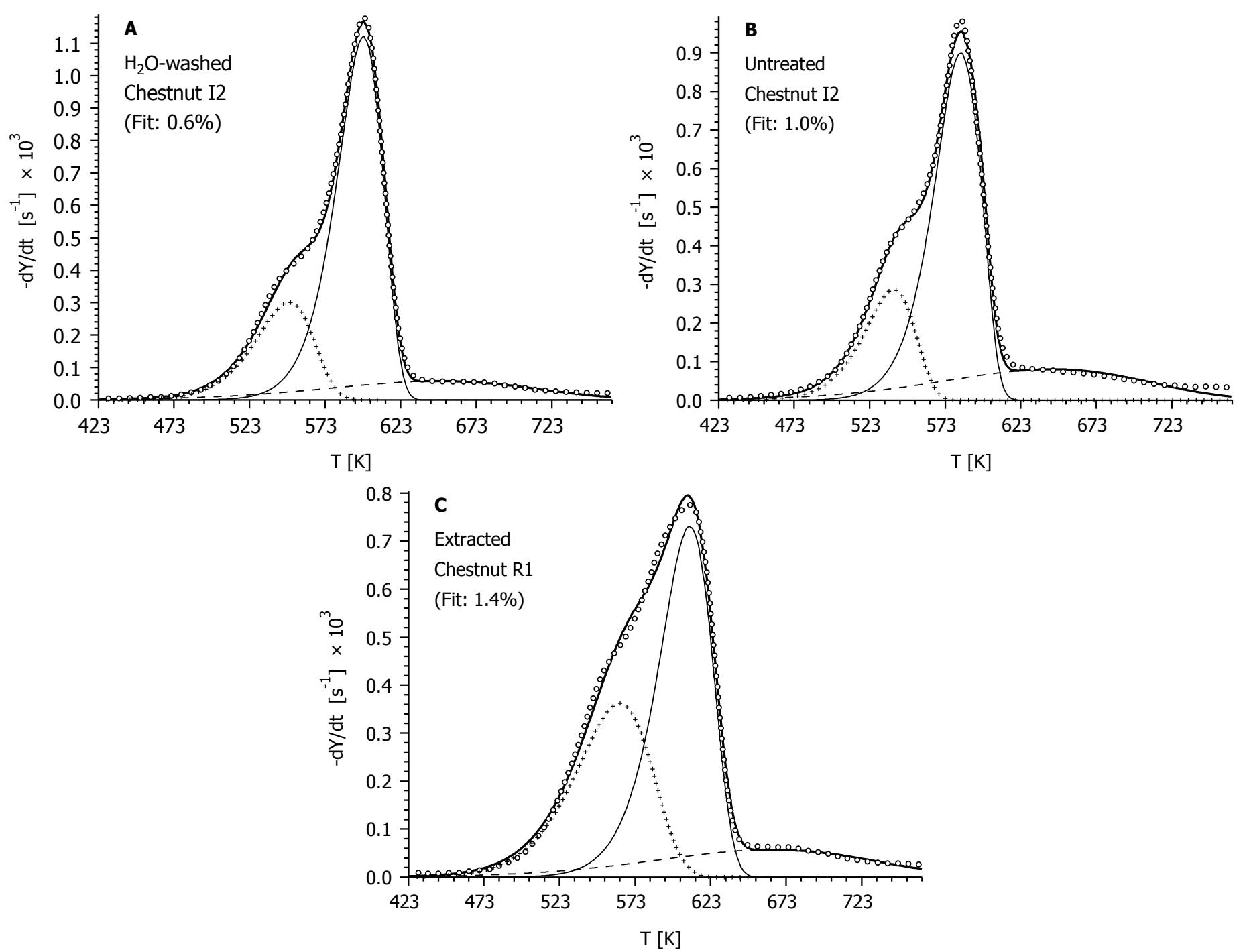

Figure 6. Comparison between the observed ( $\circ \circ$ o) and simulated (-) DTG curves employing the three-step model with variable $E_{1}$ and $E_{2}$ parameters. The best fit (A), an average fit (B) and the worse fit (C) are shown. Thin lines of different styles denote the simulated curves of the partial reactions. (See Table 5 for the corresponding parameters.)

The activation energies, $E_{h c}$ and $E_{c}$, do not vary to a large extent with the pre-treatments and appear to be essentially dependent on the sample origin. For instance, the values estimated for the cellulose fraction are always high for the sample $\mathrm{F}$ and low for the sample R1. As learned from extensive studies on the thermal behavior of cellulose ${ }^{33}$ high activation energies can be associated with more homogenous holocellulose fractions (for instance, higher chemical homogeneity in the case of hemicelluloses, or a more uniform degree of polymerization and/or a more even distribution of catalytic ions in the case of cellulose). The preexponential factors are essentially related to the peak temperatures of the three components (a given couple of activation energy and peak temperature defines uniquely the pre-exponential factor).

The kinetic parameters estimated for the pre-treated samples confirm the trends already observed from the analysis of the experimental curves. They are again qualitatively similar, though smaller variations and with some scatter are found for acetone extraction. For simplicity, the discussion is limited to hot water washing only. The most important effect is an increase in the amount of volatiles generated from the cellulose fraction 
(means for $\mathrm{c}_{\mathrm{c}}$ vary from 42 to $50 \%$ ), whose peak is well defined and only slightly covered by the other two pseudo-components. The stoichiometric coefficients for the hemicellulose and lignin zone are less affected (means for $\mathrm{c}_{\mathrm{h}}$ and $\mathrm{c}_{\mathrm{l}}$ vary from 18 to 20 and from 16 to $12 \%$, respectively). Furthermore, in relation to the amount of volatiles generated, it can be noted that the augmentation in the former zone is roughly compensated by the diminution in the latter. However, given the significant overlap between these two reaction zones and the increase in the amount of volatiles generated from extracted lignin observed in the experiments (Fig.3), the truly meaningful information that can be gained from the model results is that the total amount of volatiles generated $\left(\mathrm{c}_{\mathrm{h}}+\mathrm{c}_{1}\right)$ remains roughly constant $(33.8$ and $32.6 \%$ for untreated and hot water washed samples). Hence, the alterations induced in the cellulose fraction are the most important factors directly responsible for the observed diminution in the char yields.

Part of the information reported in Tables 4, 6 can be used to evaluate the consistence between model predictions and experimental measurement. For instance, the displacement at higher temperatures of the hemicellulose and cellulose zone, following extraction and hot water washing, is both observed and predicted. The peak widths provide information about the dynamics of the three volatile fractions. In accordance with the observed enlargement of the temperature range, $\mathrm{T}_{\text {offset(c) }}-\mathrm{T}_{\text {onset(hc), }}$, caused by hot water washing, the peak widths for the hemicellulose and cellulose components increase.

The experimental uncertainties have also been evaluated for the kinetic parameters (Tables 3, 5) and the model predictions (Tables 4,6) using the same definitions as in Tables 2A-2B. The experimental uncertainties of Estimation 1 are always much lower than the standard deviations on both kinetic parameters and predictions of the characteristic variables. The same results are also obtained for the experimental uncertainties of Estimation 2 in relation to the hemicellulose and cellulose pseudo-components. In some cases, for the lignin pseudo-component, standard deviations and experimental uncertainties present comparable values. This feature is most likely ensuing from the excessive simplification introduced by the one-step model for the complicated degradation kinetics of the lignin macromolecule and the significant sensitivity of its low decomposition rate to small alterations in the base line of the thermogravimetric experiments.

\section{CONCLUSIONS}

The widely recognized importance of renewable energy leads to an increased exploitation of biomass materials with chemico-physical properties often highly different from those of the species usually investigated. This study represent the first attempt to quantify, in terms of kinetic constants, these effects using chestnut which, following the results of previous experimental analyses ${ }^{2,3}$, report significant differences in the chemical composition and degradation characteristics with respect to standard hardwoods (i.e. beech). The influences of sample origin (five samples from different geographical areas) and pre-treatments 
(extraction, which mainly removes extractives, and hot water washing, which mainly eliminates inorganic matter) have been examined by means of thermogravimetry. Furthermore, experimental uncertainties about the repeatability of experiments/procedures and reproducibility of sample properties have been accurately evaluated.

The thermogravimetric curves, measured for a heating rate of $5 \mathrm{~K} / \mathrm{min}$, show a significant influence of the origin. In all cases, the differences between chestnut and beech have been confirmed, that is, an anticipation in the peak rate of about $20-40 \mathrm{~K}$ and higher yields of char (22-28\% versus $17 \%$ ). Furthermore, though extraction and hot water washing act to reduce differences, peculiarities due to species (chestnut versus beech) and sample origin are preserved. Compared with hot water washing, extraction is less effective for the modification of the characteristic reaction temperatures, most likely as consequence of the very slow and flat degradation rates attained by extractives over the entire temperature range examined. The char yield is always significantly reduced by the two pre-treatments, as a consequence of the reduction in the catalytic action exerted by the inorganic matter for the selectivity and rate of the charring reactions and the intrinsic contribution of extractives to product distribution (these components degrade to char for about 50\%). Cleavage of some chemical bonds may also play a role in these issues.

The thermogravimetric curves of chestnut samples obtained with and without pre-treatment are interpreted by the widely used three-step devolatilization mechanism for the pseudo-components hemicellulose, cellulose and lignin. The applicability of a low value $(46 \mathrm{~kJ} / \mathrm{mol})$ for the activation energy for the volatiles released by the lignin component is confirmed. Accurate predictions of the rate curves require single curve evaluations which produce activation energies for the hemicellulose and cellulose fractions affected mainly by sample origin. On the contrary, pre-treatments (especially hot water washing) affect the amount of volatiles generated from the three components. Alterations in the decomposition kinetics of the cellulose fraction appear to be responsible for the diminution in the char yield.

The unified devolatilization mechanism, proposed by Grønli et al. ${ }^{1}$ and based on the same activation energies for all the samples, is still applicable when, for the engineering practice, higher deviations (about twice of the ones observed earlier for woods with more standard properties) can be accepted. Variability in the other model parameters, especially in the stoichiometric coefficients, takes into account sample peculiarities.

Based on the evaluation of a significant number of experiments, it can be stated that the experimental uncertainties associated with the execution of pre-treatments and thermogravimetric runs and sampling strategy are, in general, very small for both kinetic parameters and devolatilization characteristics . 


\section{NOMENCLATURE}

\section{Symbols}

$\alpha$ volatile fraction
A pre-exponential factor
$\mathrm{c}_{\mathrm{j}}$ fraction of volatiles produced by the $\mathrm{jth}$ component
E activation energy

FWHM full width at half maximum of the DTG curve

$\mathrm{h}$ absolute value of the maximum of the observed variable

M number of components

$\mathrm{N}_{\exp }$ number of experimental curves

$\mathrm{N}_{\mathrm{k}}$ number of points for the generic thermogravimetric curve

m sample mass

$\mathrm{T}$ temperature

$\mathrm{T}_{\text {initial }}$ temperature corresponding to $\mathrm{Y}=0.975$

$\mathrm{T}_{\text {peak }}$ temperature of the maximum devolatilization rate

$\mathrm{T}_{\text {onset(hc) }}$ extrapolated temperature for the beginning of hemicellullose decomposition

$\mathrm{T}_{\text {shoulder }}$ temperature corresponding to the hemicellulose shoulder

$\mathrm{T}_{\text {offset(c) }}$ extrapolated temperature for the termination of cellulose decomposition (and the beginning of lignin tail)

$\mathrm{t}$ time

$\mathrm{Y}$ solid mass fraction

$Y_{773}$ char yield as percent of the initial solid mass

\section{Subscripts}

c cellulose

e1 first fraction of extractives

e2 second fraction of extractives

hc hemicellulose

1 lignin

peak peak of the DTG (devolatilization rate) curve

shoulder hemicellulose shoulder

offset(c) cellulose offset

onset(hc) hemicellulose onset

\section{Superscripts}

calc calculated

obs observed 
Várhegyi et al., Effects of sample origin, extraction and hot water washing on devolatilization kinetics, Page 18 of 26

\section{Acknowledgments}

The research was supported by the Norwegian Ferroalloy Producers Association (FFF), ENERGOS ASA and the Norwegian Research Council through the NYTEK and KLIMATEK programme (Norway), the Hungarian National Research Fund through contracts OTKA Grants T037704 and T37705 (Hungary), and MIUR (Italy).

\section{REFERENCES}

1) Grønli, M. G.; Várhegyi, G.; Di Blasi, C. Thermogravimetric analysis and devolatilization kinetics of wood, Ind. Eng. Chem. Res. 2002, 41, 4201.

2) Di Blasi, C.; Branca, C.; Santoro, A.; Gonzalez Hernandez, E. Pyrolytic behaviour and products of some wood varieties, Combust. Flame 2001, 124, 165.

3) Di Blasi, C.; Branca, C.; Santoro, A.; Perez Bermudez, R. A. Weight loss dynamics of wood chips under fast radiative heating, J. Anal. Appl. Pyrolysis 2001, 57, 77.

4) Theander, O. Cellulose, hemicellulose and extractives, in Fundamentals of Biomass Thermochemical Conversion, (R. P. Overend, T. A. Milne, L. K. Mudge, Eds.), Elsevier, London, 1985, pp. 35-60.

5) Jenkins, B. M.; Bakker, R. R.; Wei, J. B. On the properties of washed straw, Biomass and Bioenergy 1996, 10, 177.

6) Turn, S. Q.; Kinoshita, C. M.; Ishimura, D. M. Removal of inorganic constituents of biomass by mechanical dewatering and leaching, Biomass and Bioenergy 1997, 12, 242.

7) Jensen, A.; Dan-Johansen, K.; Wojtowicz, M. A.; Serio, M. A. TG-FTIR study on the influence of potassium chloride on wheat straw pyrolysis, Energy \& Fuels 1998, 12, 929.

8) Di Blasi, C.; Branca, C.; D'Errico, G. Degradation characteristics of straw and washed straw, Thermochimica Acta 2000, 364, 133.

9) Várhegyi, G.; Szabó, P.; Antal, M. J. Reaction kinetics of the thermal decomposition of cellulose and hemicellulose in biomass materials. In Advances in Thermochemical Biomass Conversion (A. V. Bridgwater Ed.) Vol 2, Blackie Academic and Professional, London, 1994, pp. 760-771.

10) Antal, M. J.; Várhegyi, G. Cellulose pyrolysis kinetics: the current state of knowledge, Ind. Eng. Chem. Res. 1995, $34,703$.

11) Mészáros, E.; Várhegyi, G.; Jakab, E.; Marosvölgyi, B. Thermogravimetric and reaction kinetic analysis of biomass samples from an energy plantation, Energy Fuels 2004, 18, 497-507.

12) Teng, H.S.; Lin, H.C.; Ho, J.A. Thermogravimetric analysis on global mass loss kinetics of rice hull pyrolysis. Ind. Eng. Chem. Res. 1997, 36, 3974.

13) Teng , H.; Wei ,Y.C. Thermogravimetric studies on the kinetics of rice hull pyrolysis and the influence of water treatment Ind. Eng. Chem. Res. 1998, 37, 3806.

14) Órfão, J. J.; M.; Antunes, F. J. A.; Figueiredo, J. L. Pyrolysis kinetics of lignocellulosic materials - 3 independent reactions model. Fuel 1999, 78, 349.

15) Helsen, L.; Van den Bulck, E. Kinetics of the low-temperature pyrolysis of chromated copper arsenate-treated wood. J Anal Appl Pyrol 2000, 53, 51.

16) Manyà, J. J.; Velo, E.; Puigjaner L. Kinetics of biomass pyrolysis: a reformulated three-parallel reaction model. Ind. Eng. Chem. Res. 2003, 42, 434.

17) Caballero, J. A., Conesa J. A., Font R., Marcilla A., Pyrolysis kinetics of almond shells and olive stones considering their organic fractions, J. Anal. Appl. Pyrol. 1997, 42, 159. 
18) Caballero, J. A.; Conesa, J. A.; Marcilla A. Thermogravimetric analysis of olive stones with sulphuric acid treatment, J. Anal. Appl. Pyrol. 1997,. 44, 75.

19) Conesa, J. A.; Marcilla A.; Caballero, J. A.; Font, R. Comments on the validity and utility of the different methods for kinetic analysis of thermogravimetric data, J. Anal. Appl. Pyrol. 2001, 58-59, 617.

20) Müller-Hagedorn, M.; Bockhorn, H.; Krebs, L.; Müller U. A comparative kinetic study on the pyrolysis of three different wood species, J. Anal. Appl. Pyrol. 2003, 68-69, 231.

21) Burnham, A. K.; Braun, L. R. Global kinetic analysis of complex materials, Energy \& Fuels 1999, 13, 1.

22) Di Blasi, C.; Branca C. Kinetics of primary product formation from wood pyrolysis, Ind. Eng. Chem. Res. 2001, $40,5547$.

23) Branca, C.; Di Blasi, C. Kinetics of the isothermal degradation of wood in the temperature range 528-708K, $J$. Anal. Appl. Pyrol. 2003, 67, 207.

24) Várhegyi, G.; Antal, M. J.; Jakab, E.; Szabó, P. Kinetic modelling of biomass pyrolysis, J. Anal. Appl. Pyrolysis , 1997, 42, 73 .

25) Antal, M. J.; Allen, S. G.; Dai, X.; Shimizu, B.; Tam, M. S.; Grønli, M. G. Attainment of the theoretical yield of carbon from biomass, Ind. Eng. Chem. Res. 2000, 39, 4024

26) Ahmed, A.; Pakdel, H.; Roy, C.; Kaliaguine, S. Characterization of the solid residues of vacuum pyrolysis of populus tremuloides, J. Anal Appl Pyrol 1989, 14, 281.

27) Roy, C.; Pakdel, H.; Brouillard, D. The role of extractives during vacuum pyrolysis of wood, J. of Applied Polymer Science 1990, 41, 337.

28) Jenkins, B. M.; Bakker, R. R.; Baxter, L. L.; Gilmer, J. H.; Wei, J. B. Combustion characteristics of leached biomass, in Developments in Thermochemical Biomass Conversion, (A. V. Bridgwater, D. G. B. Boocock Eds.) Vol 2, Blackie Academic \& Professionals, London, 1997, pp. 1316-1330.

29) Krieger Brockett, B.; Rodriguez, I. Woody and herbaceous biomassfeeds - how can we study their composition and their pyrolysis products?, in Progress in Thermochemical Biomass Conversion, (A. V. Bridgwater Ed.) Vol 2, Blackwell Science, London, 2001, pp. 1011-1024.

30) Várhegyi, G.; Antal, M. J.; Szekely, T.; Szabó, P. Kinetics of the thermal decomposition of cellulose, hemicellulose, and sugar cane bagasse, Energy \& Fuels 1989, 3, 329.

31) Várhegyi, G.; Szabó, P.; Antal, M. J., Jr. Kinetics of the thermal decomposition of cellulose under the experimental conditions of thermal analysis. Theoretical extrapolations to high heating rates. Biomass Bioenergy, 1994, 7, 69-74

32) Szabó, P.; Várhegyi, G.; Till, F.; Faix, O. Thermogravimetric/mass spectrometric characterization of two energy crops, Arundo donax and Miscanthus sinensis, J Anal Appl Pyrol 1996, 36, 179-190.

33) Antal, M. J.; Várhegyi, G.; Jakab, E. Cellulose pyrolysis: Revisited, Ind. Eng. Chem. Res., 1998, 37, 1267. 
Table 1. Proximate analysis and extractive content of the samples

A. Chestnut wood and beech

\begin{tabular}{|c|c|c|c|c|c|}
\hline \multicolumn{2}{|l|}{ Sample } & $\begin{array}{c}\mathrm{VM} \\
(\mathrm{wt} \%)\end{array}$ & $\begin{array}{l}\text { Fix-C } \\
(\mathrm{wt} \%)\end{array}$ & $\begin{array}{c}\text { Ash } \\
\text { (wt\%) }\end{array}$ & $\begin{array}{c}\text { Extractives } \\
(\mathrm{wt} \%)\end{array}$ \\
\hline \multicolumn{2}{|c|}{ F (untreated chestnut wood from France) } & 84.5 & 15.4 & 0.2 & 3.3 \\
\hline \multicolumn{2}{|l|}{ FE (F after extraction) } & 83.7 & 16.2 & 0.2 & - \\
\hline \multicolumn{2}{|l|}{$\mathrm{FW}\left(\mathrm{H}_{2} \mathrm{O}\right.$-washed F) } & 88.5 & 11.2 & 0.3 & - \\
\hline \multicolumn{2}{|c|}{ I1 (untreated chestnut wood from Italy) } & 76.4 & 22.4 & 1.2 & 16.0 \\
\hline \multicolumn{2}{|c|}{ I1E (I1 after extraction) } & 83.2 & 15.3 & 1.5 & - \\
\hline \multicolumn{2}{|l|}{ I1W $\left(\mathrm{H}_{2} \mathrm{O}\right.$-washed I1) } & 87.2 & 12.1 & 0.7 & - \\
\hline \multicolumn{2}{|c|}{ I2 (untreated chestnut wood from Italy) } & 79.2 & 19.9 & 0.9 & 8.5 \\
\hline \multicolumn{2}{|c|}{ I2E (I2 after extraction) } & 80.5 & 18.5 & 1.0 & - \\
\hline \multicolumn{2}{|l|}{$\mathrm{I} 2 \mathrm{~W}\left(\mathrm{H}_{2} \mathrm{O}\right.$-washed $\left.\mathrm{R} 1\right)$} & 87.0 & 12.3 & 0.7 & - \\
\hline \multicolumn{2}{|c|}{ R1 (untreated chestnut wood from Russia) } & 82.0 & 17.9 & 0.1 & 5.8 \\
\hline \multicolumn{2}{|c|}{ R1E (R1 after extraction) } & 84.7 & 15.2 & 0.1 & - \\
\hline \multicolumn{2}{|c|}{$\mathrm{R} 1 \mathrm{~W}\left(\mathrm{H}_{2} \mathrm{O}\right.$-washed $\left.\mathrm{R} 1\right)$} & 85.1 & 14.7 & 0.2 & \\
\hline \multicolumn{2}{|c|}{ R2 (untreated chestnut wood from Russia) } & 82.4 & 17.4 & 0.2 & 8.1 \\
\hline \multicolumn{2}{|c|}{ R2E (R2 after extraction) } & 84.9 & 14.9 & 0.2 & - \\
\hline \multicolumn{2}{|c|}{$\mathrm{R} 2 \mathrm{~W}\left(\mathrm{H}_{2} \mathrm{O}\right.$-washed $\left.\mathrm{R} 1\right)$} & 86.0 & 13.7 & 0.3 & - \\
\hline \multicolumn{6}{|c|}{ Means and standard deviations calculated from the chestnut samples: } \\
\hline \multicolumn{2}{|l|}{ Untreated } & 80.9 & 18.6 & 0.5 & 8.3 \\
\hline \multicolumn{2}{|l|}{$\sigma$} & 3.1 & 2.7 & 0.5 & 4.8 \\
\hline \multicolumn{2}{|l|}{ Extracted } & 83.4 & 16.0 & 0.6 & - \\
\hline \multicolumn{2}{|l|}{$\sigma$} & 1.8 & 1.5 & 0.6 & - \\
\hline \multicolumn{2}{|l|}{$\mathrm{H}_{2} \mathrm{O}$-washed } & 86.8 & 12.8 & 0.4 & - \\
\hline \multicolumn{2}{|l|}{$\sigma$} & 1.3 & 1.4 & 0.2 & - \\
\hline \multicolumn{6}{|c|}{ A forest wood for comparison: } \\
\hline \multicolumn{2}{|l|}{ Beech } & 86.5 & 13.1 & 0.4 & 2.2 \\
\hline \multicolumn{2}{|l|}{ Extracted Beech } & 85.4 & 14.2 & 0.4 & - \\
\hline \multicolumn{2}{|l|}{$\mathrm{H}_{2} \mathrm{O}$-washed beech } & 90.6 & 9.1 & 0.3 & - \\
\hline \multicolumn{6}{|c|}{ B. Proximate analysis of extracted matter and lignin } \\
\hline Sample & $\begin{array}{c}\mathrm{VM} \\
(\mathrm{wt} \%) \\
\end{array}$ & $\begin{array}{l}\text { Fix-C } \\
(\mathrm{wt} \%) \\
\end{array}$ & Ash & $(\mathrm{wt} \%)$ & \\
\hline Extractives from I1 & 66.9 & 32.7 & & .4 & \\
\hline Extractives from $\mathrm{I} 2$ & 67.4 & 31.8 & & .8 & \\
\hline Extractives from R1 & 69.0 & 29.8 & & .2 & \\
\hline Extractives from $\mathrm{R} 2$ & 67.5 & 31.2 & & .3 & \\
\hline Lignin from I1 & 51.5 & 47 & & .5 & \\
\hline Lignin from I1E & 52.7 & 43.1 & & .2 & \\
\hline Lignin from beech & 51.5 & 47.1 & & .3 & \\
\hline
\end{tabular}


Table 2. Degradation Characteristics of the Wood Samples: Temperatures, Mass Fractions, and Devolatilization Rates

A. Temperatures

\begin{tabular}{|c|c|c|c|c|c|c|c|}
\hline Sample & $\begin{array}{l}\mathrm{T}_{\text {initial }} \\
(\mathrm{K}) \\
\end{array}$ & $\begin{array}{c}\mathrm{T}_{\text {onset(hc) }} \\
(\mathrm{K}) \\
\end{array}$ & $\begin{array}{c}\mathrm{T}_{\text {shoulder }} \\
(\mathrm{K}) \\
\end{array}$ & $\begin{array}{r}\mathrm{T}_{\text {peak }} \\
(\mathrm{K}) \\
\end{array}$ & $\begin{array}{c}\mathrm{T}_{\text {offset(c) }} \\
(\mathrm{K}) \\
\end{array}$ & $\begin{array}{c}\mathrm{T}_{\text {shoulder }} \\
\mathrm{T}_{\text {onset(hc) }} \\
(\mathrm{K})\end{array}$ & $\begin{array}{c}\mathrm{T}_{\text {offset(c)- }} \\
\mathrm{T}_{\text {peak }} \\
(\mathrm{K}) \\
\end{array}$ \\
\hline $\mathrm{F}$ & 505 & 500 & 548 & 587 & 605 & 48 & 18 \\
\hline $\mathrm{FE}$ & 508 & 502 & 549 & 588 & 607 & 47 & 19 \\
\hline FW & 511 & 505 & 553 & 601 & 622 & 48 & 22 \\
\hline I1 & 505 & 501 & 553 & 587 & 615 & 52 & 28 \\
\hline I1E & 507 & 499 & 555 & 595 & 629 & 56 & 34 \\
\hline $\mathrm{I} 1 \mathrm{~W}$ & 514 & 508 & 560 & 607 & 631 & 52 & 24 \\
\hline I2 & 505 & 501 & 544 & 583 & 611 & 43 & 28 \\
\hline $\mathrm{I} 2 \mathrm{E}$ & 508 & 503 & 548 & 586 & 613 & 45 & 28 \\
\hline $\mathrm{I} 2 \mathrm{~W}$ & 514 & 507 & 551 & 599 & 624 & 44 & 25 \\
\hline $\mathrm{R} 1$ & 511 & 507 & 561 & 600 & 633 & 54 & 34 \\
\hline $\mathrm{R} 1 \mathrm{E}$ & 513 & 508 & 562 & 610 & 639 & 54 & 30 \\
\hline R1W & 516 & 506 & 562 & 613 & 641 & 56 & 28 \\
\hline $\mathrm{R} 2$ & 505 & 502 & 548 & 587 & 611 & 46 & 24 \\
\hline $\mathrm{R} 2 \mathrm{E}$ & 508 & 504 & 548 & 590 & 616 & 44 & 26 \\
\hline $\mathrm{R} 2 \mathrm{~W}$ & 515 & 508 & 553 & 604 & 627 & 45 & 24 \\
\hline
\end{tabular}

Means and standard deviations calculated for the chestnut samples:

$\begin{array}{lrrrrrrr}\text { Untreated } & 506 & 502 & 551 & 589 & 615 & 49 & 26 \\ \sigma & 3 & 3 & 7 & 6 & 11 & 4 & 6 \\ \text { Extracted } & 509 & 503 & 553 & 594 & 621 & 49 & 27 \\ \sigma & 2 & 3 & 6 & 10 & 13 & 5 & 5 \\ \mathrm{H}_{2} \mathrm{O} \text {-washed } & 514 & 507 & 556 & 605 & 629 & 49 & 24 \\ \sigma & 2 & 1 & 5 & 6 & 8 & 5 & 2\end{array}$

A forest wood for comparison:

$\begin{array}{llllllll}\text { Beech } & 519 & 512 & 567 & 623 & 644 & 55 & 21 \\ \text { Extracted beech } & 521 & 512 & 563 & 624 & 644 & 51 & 21 \\ \mathrm{H}_{2} \mathrm{O} \text {-washed } & 524 & 514 & 562 & 631 & 651 & 48 & 20\end{array}$

beech

Experimental uncertainty:

Estimation 2

1.1

$\begin{array}{lll}0.5 & 1.4 & 0.6\end{array}$

0.5

1.6

0.3

Estimation 2

0.8

0.6

1.3

0.8

0.6

1.2

1.0 
Table 2, continued:

B. Mass Fractions and Devolatilization Rates

\begin{tabular}{|c|c|c|c|c|c|c|}
\hline Sample & $Y_{\text {shoulder }}$ & $Y_{\text {peak }}$ & $Y_{773}$ & $\begin{array}{c}-(\mathrm{dY} / \mathrm{dt})_{\text {shoulder }} \\
\times 10^{3}\left(\mathrm{~s}^{-1}\right)\end{array}$ & $\begin{array}{c}-(\mathrm{dY} / \mathrm{dt})_{\text {peak }} \\
\times 10^{3}\left(\mathrm{~s}^{-1}\right)\end{array}$ & $\begin{array}{c}(\mathrm{dY} / \mathrm{dt})_{\text {shoulder }} / \\
(\mathrm{d} Y / \mathrm{dt})_{\text {peak }}\end{array}$ \\
\hline $\mathrm{F}$ & 0.83 & 0.51 & 0.22 & 0.43 & 1.29 & 0.33 \\
\hline $\mathrm{FE}$ & 0.84 & 0.52 & 0.23 & 0.41 & 1.28 & 0.32 \\
\hline FW & 0.84 & 0.46 & 0.17 & 0.40 & 1.28 & 0.31 \\
\hline I1 & 0.82 & 0.58 & 0.28 & 0.42 & 0.89 & 0.47 \\
\hline I1E & 0.81 & 0.52 & 0.20 & 0.42 & 0.88 & 0.48 \\
\hline I1W & 0.82 & 0.45 & 0.17 & 0.40 & 1.17 & 0.34 \\
\hline $\mathrm{I} 2$ & 0.85 & 0.54 & 0.24 & 0.44 & 0.98 & 0.45 \\
\hline $\mathrm{I} 2 \mathrm{E}$ & 0.84 & 0.53 & 0.22 & 0.46 & 1.03 & 0.45 \\
\hline $\mathrm{I} 2 \mathrm{~W}$ & 0.85 & 0.45 & 0.16 & 0.41 & 1.18 & 0.35 \\
\hline R1 & 0.80 & 0.52 & 0.23 & 0.47 & 0.77 & 0.62 \\
\hline $\mathrm{R} 1 \mathrm{E}$ & 0.80 & 0.44 & 0.19 & 0.48 & 0.77 & 0.61 \\
\hline R1W & 0.83 & 0.45 & 0.19 & 0.40 & 0.94 & 0.43 \\
\hline $\mathrm{R} 2$ & 0.83 & 0.51 & 0.22 & 0.44 & 1.12 & 0.40 \\
\hline $\mathrm{R} 2 \mathrm{E}$ & 0.84 & 0.50 & 0.19 & 0.44 & 1.16 & 0.37 \\
\hline $\mathrm{R} 2 \mathrm{~W}$ & 0.85 & 0.46 & 0.18 & 0.40 & 1.17 & 0.34 \\
\hline \multicolumn{7}{|c|}{ Means and standard deviations calculated for the chestnut samples: } \\
\hline Untreated & 0.83 & 0.53 & 0.24 & 0.44 & 1.01 & 0.45 \\
\hline$\sigma$ & 0.02 & 0.03 & 0.02 & 0.02 & 0.20 & 0.11 \\
\hline Extracted & 0.83 & 0.50 & 0.21 & 0.44 & 1.03 & 0.45 \\
\hline$\sigma$ & 0.02 & 0.04 & 0.02 & 0.03 & 0.21 & 0.11 \\
\hline $\mathrm{H}_{2} \mathrm{O}$-washed & 0.84 & 0.45 & 0.17 & 0.40 & 1.15 & 0.36 \\
\hline$\sigma$ & 0.01 & 0.00 & 0.01 & 0.01 & 0.13 & 0.05 \\
\hline \multicolumn{7}{|c|}{ A forest wood for comparison: } \\
\hline Beech & 0.81 & 0.40 & 0.19 & 0.41 & 0.99 & 0.42 \\
\hline Extracted beech & 0.83 & 0.40 & 0.18 & 0.40 & 1.03 & 0.39 \\
\hline $\begin{array}{l}\mathrm{H}_{2} \mathrm{O} \text {-washed } \\
\text { beech }\end{array}$ & 0.85 & 0.36 & 0.12 & 0.38 & 1.21 & 0.31 \\
\hline \multicolumn{7}{|c|}{ Experimental uncertainty: } \\
\hline Estimation 1 & 0.005 & 0.005 & 0.006 & 0.007 & 0.024 & 0.009 \\
\hline Estimation 2 & 0.010 & 0.014 & 0.016 & 0.007 & 0.016 & 0.006 \\
\hline
\end{tabular}


Table 3. Parameters for the three-step unified devolatilization mechanism using activation energies from an earlier work $^{\text {a }}$

\begin{tabular}{|c|c|c|c|c|c|c|c|}
\hline Sample & $\begin{array}{l}\text { Fit } \\
(\%)\end{array}$ & $\begin{array}{l}\log A_{h c} \\
\left(\log s^{-1}\right)\end{array}$ & $\begin{array}{c}\log A_{c} \\
\left(\log s^{-1}\right) \\
\end{array}$ & 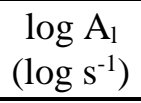 & $c_{h c}$ & $\mathrm{c}_{\mathrm{c}}$ & $\mathrm{c}_{1}$ \\
\hline F & 2.2 & 7.2 & 18.8 & 0.7 & 0.21 & 0.43 & 0.15 \\
\hline $\mathrm{FE}$ & 2.2 & 7.2 & 18.8 & 0.7 & 0.20 & 0.43 & 0.14 \\
\hline FW & 1.2 & 7.0 & 18.3 & 0.7 & 0.23 & 0.48 & 0.13 \\
\hline I1 & 2.3 & 7.0 & 18.6 & 0.6 & 0.25 & 0.31 & 0.17 \\
\hline I1E & 3.5 & 6.8 & 18.3 & 0.9 & 0.28 & 0.31 & 0.20 \\
\hline I1W & 1.4 & 6.9 & 18.0 & 0.7 & 0.26 & 0.46 & 0.13 \\
\hline $\mathrm{I} 2$ & 2.2 & 7.0 & 18.8 & 0.8 & 0.27 & 0.31 & 0.18 \\
\hline $\mathrm{I} 2 \mathrm{E}$ & 2.5 & 6.9 & 18.7 & 0.9 & 0.30 & 0.31 & 0.17 \\
\hline $\mathrm{I} 2 \mathrm{~W}$ & 1.5 & 6.8 & 18.3 & 0.8 & 0.27 & 0.43 & 0.14 \\
\hline $\mathrm{R} 1$ & 1.7 & 6.6 & 18.0 & 0.7 & 0.38 & 0.24 & 0.15 \\
\hline R1E & 2.0 & 6.6 & 17.8 & 0.8 & 0.40 & 0.26 & 0.15 \\
\hline R1W & 2.1 & 6.6 & 17.8 & 0.9 & 0.30 & 0.35 & 0.16 \\
\hline $\mathrm{R} 2$ & 1.8 & 7.1 & 18.7 & 0.8 & 0.24 & 0.38 & 0.17 \\
\hline R2E & 2.3 & 7.0 & 18.6 & 0.8 & 0.24 & 0.41 & 0.17 \\
\hline $\mathrm{R} 2 \mathrm{~W}$ & 1.5 & 6.9 & 18.2 & 0.8 & 0.25 & 0.45 & 0.13 \\
\hline \multicolumn{8}{|c|}{ Means and standard deviations calculated for the chestnut samples: } \\
\hline Untreated & 2.1 & 7.0 & 18.6 & 0.7 & 0.27 & 0.33 & 0.16 \\
\hline$\sigma$ & 0.3 & 0.2 & 0.3 & 0.1 & 0.07 & 0.08 & 0.01 \\
\hline Extracted & 2.5 & 6.9 & 18.4 & 0.8 & 0.29 & 0.34 & 0.17 \\
\hline$\sigma$ & 0.6 & 0.2 & 0.4 & 0.1 & 0.07 & 0.07 & 0.02 \\
\hline $\mathrm{H}_{2} \mathrm{O}$-washed & 1.6 & 6.9 & 18.1 & 0.8 & 0.26 & 0.43 & 0.14 \\
\hline$\sigma$ & 0.3 & 0.1 & 0.2 & 0.1 & 0.02 & 0.05 & 0.01 \\
\hline \multicolumn{8}{|c|}{ A forest wood for comparison: } \\
\hline Beech & 1.4 & 6.7 & 17.6 & 0.7 & 0.31 & 0.40 & 0.10 \\
\hline Extracted beech & 1.5 & 6.7 & 17.6 & 0.7 & 0.31 & 0.42 & 0.10 \\
\hline $\begin{array}{l}\mathrm{H}_{2} \mathrm{O} \text {-washed } \\
\text { beech }\end{array}$ & 1.7 & 6.6 & 17.3 & 0.6 & 0.30 & 0.51 & 0.08 \\
\hline \multicolumn{8}{|c|}{ Experimental uncertainty: } \\
\hline Estimation 1 & 0.07 & 0.01 & 0.02 & 0.01 & 0.004 & 0.007 & 0.004 \\
\hline Estimation 2 & 0.06 & 0.01 & 0.03 & 0.10 & 0.007 & 0.007 & 0.004 \\
\hline
\end{tabular}

${ }^{\mathrm{a}} \mathrm{E}_{\mathrm{hc}}(\mathrm{kJ} / \mathrm{mol})=100, \mathrm{E}_{\mathrm{c}}(\mathrm{kJ} / \mathrm{mol})=236$, and $\mathrm{E}_{\mathrm{l}}(\mathrm{kJ} / \mathrm{mol})=46$. 
Table 4. Characteristics of the partial peaks belonging to the parameters of Table 3

\begin{tabular}{|c|c|c|c|c|c|c|c|c|c|}
\hline Sample & $\begin{array}{c}\mathrm{T}_{\text {peak,hc }} \\
(\mathrm{K})\end{array}$ & $\begin{array}{c}\text { FWHM }_{\mathrm{hc}^{\mathrm{a}}} \\
(\mathrm{K})\end{array}$ & $\begin{array}{l}\text { Height }_{\mathrm{hc}} \\
\left(\mathrm{s}^{-1}\right) \times 100 \\
\end{array}$ & $\begin{array}{c}\mathrm{T}_{\text {peak,c }} \\
(\mathrm{K})\end{array}$ & $\begin{array}{c}\mathrm{FWHM}_{\mathrm{c}} \\
(\mathrm{K})\end{array}$ & $\begin{array}{c}\text { Height }_{c} \\
\left(\mathrm{~s}^{-1}\right) \times 100 \\
\end{array}$ & $\begin{array}{c}\mathrm{T}_{\text {peak,c }} \\
(\mathrm{K})\end{array}$ & $\begin{array}{c}\text { FWHM }_{1} \\
(\mathrm{~K})\end{array}$ & $\begin{array}{c}\text { Height }_{1} \\
\left(\mathrm{~s}^{-1}\right) \times 100\end{array}$ \\
\hline \multicolumn{10}{|c|}{ Means and standard deviations calculated for the chestnut samples: } \\
\hline Untreated & 553 & 59 & 0.130 & 593 & 30 & 0.255 & 650 & 162 & 0.048 \\
\hline$\sigma$ & 12 & 3 & 0.005 & 9 & 1 & 0.010 & 10 & 5 & 0.001 \\
\hline Extracted & 557 & 60 & 0.128 & 598 & 30 & 0.253 & 640 & 158 & 0.049 \\
\hline$\sigma$ & 12 & 3 & 0.005 & 11 & 1 & 0.009 & 11 & 5 & 0.002 \\
\hline $\mathrm{H}_{2} \mathrm{O}$-washed & 559 & 60 & 0.128 & 606 & 31 & 0.245 & 645 & 160 & 0.049 \\
\hline$\sigma$ & 8 & 2 & 0.003 & 6 & 1 & 0.005 & 13 & 6 & 0.002 \\
\hline \multicolumn{10}{|c|}{ A forest wood for comparison: } \\
\hline Beech & 570 & 62 & 0.123 & 623 & 33 & 0.235 & 654 & 165 & 0.047 \\
\hline Extracted beech & 569 & 62 & 0.123 & 623 & 32 & 0.234 & 661 & 167 & 0.047 \\
\hline $\mathrm{H}_{2} \mathrm{O}$-washed beech & 571 & 62 & 0.123 & 630 & 34 & 0.226 & 676 & 174 & 0.045 \\
\hline \multicolumn{10}{|c|}{ Experimental uncertainty: } \\
\hline Estimation 1 & 0.6 & 0.3 & 0.0010 & 0.6 & 0.1 & 0.0007 & 2.4 & 0.9 & 0.0003 \\
\hline Estimation 2 & 0.9 & 0.2 & 0.001 & 0.9 & 0.3 & 0.001 & 15.2 & 7.5 & 0.002 \\
\hline
\end{tabular}

${ }^{\text {a }}$ Full width at half maximum 
Table 5. Parameters for the three-step devolatilization mechanism without constraints on $E_{h c}$ and $E_{c}{ }^{a}$

\begin{tabular}{|c|c|c|c|c|c|c|c|c|c|}
\hline Sample & $\begin{array}{l}\text { Fit } \\
(\%)\end{array}$ & $\begin{array}{c}\mathrm{E}_{\mathrm{hc}} \\
(\mathrm{kJ} / \mathrm{mol})\end{array}$ & $\begin{array}{c}\mathrm{E}_{\mathrm{c}} \\
(\mathrm{kJ} / \mathrm{mol})\end{array}$ & $\begin{array}{l}\log A_{h c} \\
\left(\log s^{-1}\right)\end{array}$ & $\begin{array}{c}\log \mathrm{A}_{\mathrm{c}} \\
\left(\log \mathrm{s}^{-1}\right)\end{array}$ & $\begin{array}{c}\log A_{1} \\
\left(\log s^{-1}\right)\end{array}$ & $c_{h c}$ & $\mathrm{c}_{\mathrm{c}}$ & $\overline{c_{1}}$ \\
\hline$F$ & 1.1 & 133 & 268 & 10.4 & 21.7 & 0.8 & 0.20 & 0.40 & 0.17 \\
\hline $\mathrm{FE}$ & 1.2 & 138 & 257 & 10.9 & 20.7 & 0.8 & 0.18 & 0.42 & 0.16 \\
\hline FW & 0.8 & 124 & 230 & 9.4 & 17.8 & 0.8 & 0.20 & 0.49 & 0.13 \\
\hline I1 & 1.1 & 137 & 182 & 10.9 & 13.9 & 0.6 & 0.15 & 0.41 & 0.16 \\
\hline I1E & 0.7 & 130 & 154 & 10.2 & 11.1 & 0.7 & 0.16 & 0.50 & 0.14 \\
\hline I1W & 0.8 & 122 & 224 & 9.1 & 17.0 & 0.7 & 0.22 & 0.48 & 0.13 \\
\hline $\mathrm{I} 2$ & 1.0 & 140 & 182 & 11.3 & 14.1 & 0.8 & 0.15 & 0.44 & 0.16 \\
\hline $\mathrm{I} 2 \mathrm{E}$ & 1.2 & 148 & 171 & 12.0 & 13.0 & 0.8 & 0.13 & 0.48 & 0.15 \\
\hline $\mathrm{I} 2 \mathrm{~W}$ & 0.6 & 127 & 194 & 9.7 & 14.7 & 0.7 & 0.18 & 0.54 & 0.12 \\
\hline $\mathrm{R} 1$ & 0.9 & 108 & 160 & 7.7 & 11.5 & 0.7 & 0.22 & 0.42 & 0.13 \\
\hline R1E & 1.4 & 101 & 172 & 6.9 & 12.4 & 0.6 & 0.28 & 0.41 & 0.12 \\
\hline $\mathrm{R} 1 \mathrm{~W}$ & 0.8 & 109 & 175 & 7.7 & 12.6 & 0.7 & 0.21 & 0.50 & 0.11 \\
\hline $\mathrm{R} 2$ & 1.1 & 137 & 213 & 10.8 & 16.7 & 0.8 & 0.18 & 0.43 & 0.17 \\
\hline $\mathrm{R} 2 \mathrm{E}$ & 1.3 & 144 & 200 & 11.5 & 15.5 & 0.8 & 0.17 & 0.48 & 0.16 \\
\hline $\mathrm{R} 2 \mathrm{~W}$ & 0.8 & 126 & 209 & 9.6 & 15.9 & 0.7 & 0.20 & 0.50 & 0.12 \\
\hline \multicolumn{10}{|c|}{ Means and standard deviations calculated for the chestnut samples: } \\
\hline Untreated & 1.0 & 131 & 201 & 10.2 & 15.6 & 0.7 & 0.18 & 0.42 & 0.16 \\
\hline$\sigma$ & 0.1 & 13 & 42 & 1.5 & 3.9 & 0.1 & 0.03 & 0.01 & 0.02 \\
\hline Extracted & 1.1 & 132 & 191 & 10.3 & 14.5 & 0.7 & 0.19 & 0.46 & 0.15 \\
\hline$\sigma$ & 0.3 & 19 & 41 & 2.0 & 3.8 & 0.1 & 0.06 & 0.04 & 0.02 \\
\hline $\mathrm{H}_{2} \mathrm{O}$-washed & 0.8 & 122 & 206 & 9.1 & 15.6 & 0.7 & 0.20 & 0.50 & 0.12 \\
\hline$\sigma$ & 0.1 & 8 & 22 & 0.8 & 2.0 & 0.0 & 0.01 & 0.02 & 0.01 \\
\hline \multicolumn{10}{|c|}{ A forest wood for comparison: } \\
\hline Beech & 1.4 & 97 & 234 & 6.4 & 17.4 & 0.7 & 0.32 & 0.41 & 0.10 \\
\hline Extracted beech & 1.4 & 98 & 244 & 6.5 & 18.3 & 0.7 & 0.32 & 0.40 & 0.11 \\
\hline $\mathrm{H} 2 \mathrm{O}$-washed beech & 1.6 & 91 & 257 & 5.8 & 19.1 & 0.6 & 0.33 & 0.47 & 0.09 \\
\hline \multicolumn{10}{|c|}{ Experimental uncertainty: } \\
\hline Estimation1 & 0.04 & 1.2 & 4.1 & 0.14 & 0.33 & 0.01 & 0.006 & 0.004 & 0.004 \\
\hline Estimation2 & 0.04 & 0.6 & 4.8 & 0.06 & 0.42 & 0.08 & 0.007 & 0.011 & 0.004 \\
\hline
\end{tabular}

${ }^{\text {a }}$ A fixed value from earlier work $(46 \mathrm{~kJ} / \mathrm{mol})$ was used for $\mathrm{E}_{1}$ 
Table 6. Characteristics of the partial peaks belonging to the parameters of Table 5

\begin{tabular}{|c|c|c|c|c|c|c|c|c|c|}
\hline Sample & $\begin{array}{c}\mathrm{T}_{\text {peak,hc }} \\
(\mathrm{K})\end{array}$ & $\begin{array}{c}\text { FWHM }_{\mathrm{hc}^{\mathrm{a}}} \\
(\mathrm{K})\end{array}$ & $\begin{array}{l}\text { Height }_{\mathrm{hc}} \\
\left(\mathrm{s}^{-1}\right) \times 100\end{array}$ & $\begin{array}{c}T_{\text {peak }, c} \\
(\mathrm{~K})\end{array}$ & $\begin{array}{c}\mathrm{FWHM}_{\mathrm{c}} \\
(\mathrm{K})\end{array}$ & $\begin{array}{c}\text { Height }_{\mathrm{c}} \\
\left(\mathrm{s}^{-1}\right) \times 100\end{array}$ & $\begin{array}{c}\mathrm{T}_{\text {peak,c }} \\
(\mathrm{K})\end{array}$ & $\begin{array}{c}\text { FWHM }_{1} \\
(\mathrm{~K})\end{array}$ & $\begin{array}{c}\text { Height } \\
\left(\mathrm{s}^{-1}\right) \times 100 \\
\end{array}$ \\
\hline \multicolumn{10}{|c|}{ Means and standard deviations calculated for the chestnut samples: } \\
\hline Untreated & 545 & 45 & 0.172 & 590 & 35 & 0.223 & 652 & 164 & 0.048 \\
\hline$\sigma$ & 7 & 6 & 0.020 & 7 & 7 & 0.046 & 15 & 7 & 0.002 \\
\hline Extracted & 547 & 45 & 0.173 & 594 & 38 & 0.209 & 650 & 162 & 0.048 \\
\hline$\sigma$ & 9 & 9 & 0.027 & 9 & 7 & 0.046 & 11 & 5 & 0.001 \\
\hline $\mathrm{H}_{2} \mathrm{O}$-washed & 553 & 49 & 0.157 & 605 & 35 & 0.217 & 654 & 164 & 0.048 \\
\hline$\sigma$ & 4 & 4 & 0.010 & 5 & 4 & 0.024 & 6 & 3 & 0.001 \\
\hline \multicolumn{10}{|c|}{ A forest wood for comparison: } \\
\hline Beech & 570 & 64 & 0.120 & 623 & 33 & 0.233 & 661 & 167 & 0.047 \\
\hline Extracted beech & 571 & 63 & 0.121 & 624 & 31 & 0.242 & 658 & 166 & 0.047 \\
\hline $\mathrm{H}_{2} \mathrm{O}$-washed beech & 574 & 69 & 0.111 & 631 & 31 & 0.245 & 665 & 170 & 0.046 \\
\hline \multicolumn{10}{|c|}{ Experimental uncertainty: } \\
\hline Estimation 1 & 1.5 & 0.9 & 0.0022 & 0.9 & 0.5 & 0.0045 & 0.6 & 0.3 & 0.0002 \\
\hline Estimation 2 & 0.9 & 0.3 & 0.0008 & 0.7 & 0.6 & 0.0049 & 12.6 & 6.0 & 0.0016 \\
\hline
\end{tabular}

${ }^{a}$ Full width at half maximum 